\title{
URODYNAMIC ASSESSMENT IN EVALUATION OF BENIGN PROSTATIC HYPERPLASIA
}

\author{
Manjunath Shettyํ․ A. Siva Sai Bharadwaja², Mohan Chandra Kumar Suvarna 3 , Antony Thomas 4
}

1 Professor, Department of Urology, Father Muller Medical College Hospital, Kankanady, Mangalore. ${ }^{2}$ Resident, Department of Urology, Father Muller Medical College Hospital, Kankanady, Mangalore. 3 Professor, Department of Urology, Father Muller Medical College Hospital, Kankanady, Mangalore. ${ }^{4}$ Resident, Department of Urology, Father Muller Medical College Hospital, Kankanady, Mangalore.

\section{ABSTRACT}

More than $50 \%$ of aging men suffer from lower urinary tract symptoms. Lower Urinary Tract Symptoms (LUTS) are very common symptoms among aging men. LUTS may be either due to storage or voiding disorder of bladder. The evaluation of BPH either due to storage or voiding disorder can be completed by urodynamic studies. A small percentage of cases with neurogenic component can be due to detrusor instability for which surgery alone gives poor outcome. Management of these patients are complex. The present study centres on the patients with BPH having bladder outlet obstruction associated with the neurogenic component.

\section{KEYWORDS}

BPH, LUTS, Urodynamic Study.

HOW TO CITE THIS ARTICLE: Shetty M, Bharadwaja ASS, Suvarna MCK, et al. Urodynamic assessment in evaluation of benign prostatic hyperplasia. J. Evolution Med. Dent. Sci. 2016;5(50):3185-3186, DOI: 10.14260/jemds/2016/738

\section{INTRODUCTION}

More than $50 \%$ of aging men suffer from Lower Urinary Tract Symptoms (LUTS) due to Benign Prostatic Hyperplasia (BPH) and is the most common condition in aging men. ${ }^{1}$ LUTS may be either due to storage or voiding disorder of bladder. Moderateto-severe symptoms occur in $40 \%$ and $80 \%$ of men after the age 60 and by 80 years, respectively. Nearly, all men develop subclinical BPH by the age of 50 years. Benign Prostatic Hyperplasia (BPH) may cause infravesical obstruction in nearly $50 \%$ of men over 60 years of age. Other important changes observed with age include an increased prevalence of involuntary detrusor contractions and increased Post Void Residual (PVR) urine volume. The evaluation of BPH either due to storage or voiding disorder can be complimented by urodynamic studies. ${ }^{2}$ A small percentage of cases with neurogenic component can be associated due to detrusor instability, for which surgery alone gives poor outcome. Management of these patients are debatable. The present study centres on the BPH patients with pure bladder outlet obstruction or bladder outlet obstruction associated with the neurogenic component. ${ }^{3}$ The evaluation of BPH patients by IPSS symptom score, by anatomical and functional assessment and urodynamic evaluation consisting of cystometrogram, pressure flow studies, uroflowmetry and post void residual urine. 4,5 The study was conducted on 60 patients who were admitted in Father Muller Medical College Hospital between August 2011 and September 2015 with Lower Urinary Tract Symptoms (LUTS) having BPH.

\section{OBJECTIVES OF THE STUDY}

1. To study the urodynamic evaluation in the assessment of Benign Prostatic Hyperplasia (BPH).

Financial or Other, Competing Interest: None.

Submission 27-02-2016, Peer Review 31-05-2016,

Acceptance 06-06-2016, Published 21-06-2016.

Corresponding Author:

Dr. Manjunath Shetty,

Professor,

Department of Urology,

Father Muller Medical College Hospital,

Kankanady, Mangalore-575002.

E-mail: manjunathshetty51@gmail.com

DOI: $10.14260 /$ jemds $/ 2016 / 738$
2. To identify the contribution of neurogenic component to bladder outlet obstruction due to BPH.

3. To assess neurovesical dysfunction either pure or secondary as a contributing factor for bladder outlet obstruction in BPH patients.

4. To modify treatment protocol as to improve the treatment outcome in patients with BPH.

\section{MATERIALS AND METHODS}

The study was conducted on 60 male patients who were admitted in Father Muller Medical College Hospital between August 2011 and September 2015 with a diagnosis of Lower Urinary Tract Symptoms (LUTS) and BPH. On admission detailed history was taken and examined in detail to evaluate the cause; clinically all were diagnosed to have BPH following which patients were subjected for urodynamic evaluation. The management was based on the urodynamic evaluation.

\section{Inclusion Criteria}

Male patients having Lower Urinary Tract Symptoms (LUTS). Patients with clinically diagnosed BPH. Age more than 50 yrs.

\section{Exclusion Criteria}

Patients with stricture urethra.

Patients with carcinoma prostate.

\section{RESULTS}

\section{Age Distribution}

In our study of urodynamic assessment of patients with BPH we found that $43 \%$ of patients with $\mathrm{BPH}$ present in the age group 61-70 years. ${ }^{6}$

\begin{tabular}{|c|c|c|}
\hline & Frequency & Percent \\
\hline $51-60$ & 13 & 21.7 \\
\hline $61-70$ & 26 & 43.3 \\
\hline $71-80$ & 17 & 28.3 \\
\hline Above 80 & 4 & 6.7 \\
\hline Total & $\mathbf{6 0}$ & $\mathbf{1 0 0 . 0}$ \\
\hline
\end{tabular}

Symptoms Assessment Type of LUTS

\begin{tabular}{|c|c|c|}
\hline & Frequency & Percent \\
\hline ST & 17 & 28.3 \\
\hline V & 43 & 71.7 \\
\hline Total & $\mathbf{6 0}$ & $\mathbf{1 0 0 . 0}$ \\
\hline
\end{tabular}

S - Storage, V - Voiding 
In our study of urodynamic assessment of patients with respect to the type of LUTS with $\mathrm{BPH}$, we found that $71.7 \%$ of patients with BPH presented with voiding symptoms. ${ }^{6}$

\section{Duration}

\begin{tabular}{|c|c|c|}
\hline & Frequency & Percent \\
\hline 6 months and below & 14 & 23.3 \\
\hline $7-12$ months & 41 & 68.3 \\
\hline Above 12 months & 5 & 8.3 \\
\hline Total & $\mathbf{6 0}$ & $\mathbf{1 0 0 . 0}$ \\
\hline
\end{tabular}

In our study of urodynamic assessment of patients with $\mathrm{BPH}$, we found that $68 \%$ (41 patents) of patients with $\mathrm{BPH}$ presented with voiding symptoms (Frequency) $>7-12$ months.

\section{Clinical Diagnosis}

All patients in the study had a clinical diagnosis of BPH.

\section{IPSS Score}

\begin{tabular}{|c|c|c|}
\hline & Frequency & Percent \\
\hline Mild & 16 & 26.7 \\
\hline Moderate & 3 & 5.0 \\
\hline Severe & 41 & 68.3 \\
\hline Total & $\mathbf{6 0}$ & $\mathbf{1 0 0 . 0}$ \\
\hline
\end{tabular}

In our study, we found that $68.3 \%$ of patients presented with severe IPSS score warranting surgery. ${ }^{6}$

\section{INVESTIGATIONS}

Type of Voiding Dysfunction on Urodynamic Assessment

\begin{tabular}{|c|c|c|}
\hline & Frequency & Percent \\
\hline NG & 21 & 35.0 \\
\hline NN & 39 & 65.0 \\
\hline Total & $\mathbf{6 0}$ & $\mathbf{1 0 0 . 0}$ \\
\hline
\end{tabular}

NG: Neurogenic, NN: Non-Neurogenic

\section{Treatment Outcome}

\begin{tabular}{|c|c|c|}
\hline & Frequency & Percent \\
\hline S + CIC & 19 & 31.7 \\
\hline S & 41 & 68.3 \\
\hline Total & $\mathbf{6 0}$ & $\mathbf{1 0 0 . 0}$ \\
\hline
\end{tabular}

\section{S: Surgery, S-CIC: Post-Surgery with CIC}

In our study we found that all patients who visited for BPH consultation needed surgery as the treatment modality. The patient with both storage and voiding disorder requires Clean Intermittent Cauterization (CIC) following surgery.7,8,9

\section{DISCUSSION}

Based on the results of the study and comparison with studies, the following inferences were drawn.

1. Age Distribution Majority of the patients presenting with $\mathrm{BPH}$ are in the age group of 61-70 yrs. and this may be explained by the fact that this age group is more vulnerable for lower urinary tract obstruction.5,6

2. Clinical Presentation: All the patients having LUTS had both storage and voiding type. The symptoms assessed by IPSS scoring system about $68.3 \%$ of patients with BPH presented has IPSS score more than 24 . About $71 \%$ of patients presented with voiding symptoms, $28 \%$ of patients presented with storage symptoms. ${ }^{7,8}$
3. Duration: Most of the patients having symptom duration within one year. Among them $68.3 \%$ showed 7-12 months of symptom duration and about $23.3 \%$ were below 6 months of symptom duration.

4. Urodynamic Evaluation: About $65 \%$ of patients with BPH were having obstructive pathology and $35 \%$ of patients with BPH having both the obstructive as well as neurogenic pathology due to detrusor instability. 10,10

5. Outcome: It has been found that the group with the obstructive pathology the outcome of surgery is good. The outcome of surgery in obstructive pathology due to BPH along with detrusor instability was sub-optional. These patients required post-operative Clean Intermittent Cauterization (CIC) to improve the post void residue. ${ }^{10}$

\section{CONCLUSION}

Urodynamic evaluation is a worthwhile investigation in patients with $\mathrm{BPH}$ as a significant proportion (More than $1 / 3^{\mathrm{rd}}$ ) is affected by neurovesical dysfunction secondary to obstructive pathology. Identifying this segment of people can improve the treatment outcome of $\mathrm{BPH}$ patients. ${ }^{10}$

\section{REFERENCES}

1. Bremen DM, Rodriguez R, Velteri RW. Development, Molecular, Biology, and physiology of the prostate. In: Wein AJ (edr). Textbook of Cambell and Walsh urology, 10 $0^{\text {th }}$ ed. Philadelphia: Elsevier, 2012;3:2533-69.

2. Thomas AW, Cannon A, Bartlett E, et al. The natural history of lower urinary tract dysfunction in men: minimum 10-year urodynamic follow-up of untreated bladder outlet obstruction. BJU Int 2005;96(9):1301-6.

3. Dorsher PT, McIntosh PM. Neurogenic bladder. Advances in urology Article ID 816274, 2012:p 16. doi:10.1155/2012/816274.

4. Parsons JK. Lifestyle factors, benign prostatic hyperplasia, and lower urinary tract symptoms. Curr Opin Urol 2011;21(1):1-4. doi: 10.1097/MOU.0b013e32834100c9.

5. Grossfeld GD, Coakley FV. Benign prostatic hyperplasia: clinical overview and the value of diagnostic imaging. Radiol Clin North Am 2000;38(1):31-47.

6. Berry SJ, Coffey DS, Walsh PC, et al. The development of human benign prostatic hyperplasia with age. J Urol 1984;132(3):474-9.

7. Chute CG, Panser LA, Girman CJ, et al. The prevalence of prostatism: a population-based survey of urinary symptoms. J Urol 1993;150(1):85-9.

8. Eckhardt MD, Venrooij VGE, Boon TA. Symptoms, prostate volume, and urodynamic findings in elderly male volunteers without and with LUTS and in patients with LUTS suggestive of benign prostatic hyperplasia. Urology 2001;58(6):966-71.

9. American Urological Society. AUA guideline on management of benign prostatic hyperplasia chapter 1: diagnosis treatment recommendations. J Urol 2003;170 (2 pt 1):530-47

10. Abrams PH, Farrar DJ, Turner-Warwick RT, et al. The results of prostatectomy: a symptomatic and urodynamic analysis of 152 patients. J Urol 1979;121(5):640-2. 